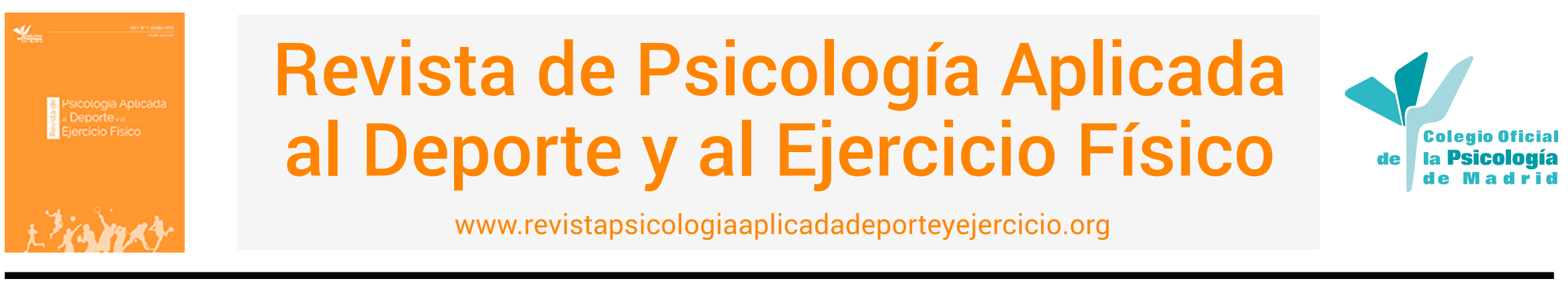

\title{
Entrevista a Virginia Calvo por Antonio José de la Cuesta
}

\section{¿Quién es Virginia Calvo?}

Nací en Madrid hace 42 años. Fui una niña bastante extrovertida y buena estudiante. Estudié BUP y COU en el Instituto Beatriz Galindo en la rama de ciencias puras. Se me daba muy bien la física y me gustaba mucho la ciencia en general.

Compaginé mis estudios con trabajos de fin de semana. En paralelo también estuve federada en atletismo durante 6 años. Salté pértiga, corrí obstáculos, hice cross y 5.000 metros en pista.

Cuando terminé la carrera de Dirección y Administración de Empresas en Madrid, me trasladé a Málaga y comenzó mi andadura como empresaria en 2004 con Atlas Informática. En 2011 fui madre por primera vez y en 2013 hice un MBA en la Cámara de Comercio.

En 2012 adquirimos Giants Gaming, club con el que ya trabajábamos, y comenzamos nuestro camino en los esports profesionales hasta la fecha. En 2015 fui madre de mi segunda hija. En 2020, fundamos Good Game Group, el conglomerado de esports más importante de España, en el que trabajamos la parte competitiva, pues tenemos Giants y otro club, x6tence; la creación de contenido, con Esportmaníacos, BCN Fighters y programas a terceros; y la creación de productos y periféricos.

\section{En 2018 se crea la Asociación de Clubs de Esports (ACE). ¿Qué aporta al sector y qué objetivos y funciones tiene?}

Al crearse la asociación, los clubes quedan unidos a la hora de tomar decisiones que afectan a los esports en Es- paña. Fue un paso importante, ya que fue la primera asociación de clubes de esports a nivel europeo. La misión que tiene la ACE es mantener la calidad en la industria y defender sus intereses; trabajar en cuestiones comunes que nos afectan a nivel organizativo, jurídico y laboral. También detectar aquellos desafíos a futuro que se presenten al sector. A fin de cuentas, los clubes somos las empresas que soportan toda la parte de jugadores que son los que acumulan el engagement más puro de la industria.

\section{España es una de las potencias europeas en esports, ¿cómo definirías el estado actual tanto a nivel nacional como en otros países? ¿Cuáles son los grandes retos a conseguir dentro del sector a medio y largo plazo?}

El sector de los esports en España está consolidado y profesionalizado y tiene un futuro muy grande por delante. En los últimos años las audiencias y el interés por los esports no han dejado de crecer, también el interés de las marcas. Los clubes, las organizaciones, los profesionales que están en él han construido un ecosistema muy sólido que, no obstante, aún tiene mucho por recorrer como digo, ya que dentro del sector de los videojuegos aún representamos una pequeña parte. Decimos habitualmente que somos un bebé que está aprendiendo a andar. Pero lo que tenemos por delante es muy ilusionante y aún tenemos mucho por conseguir a nivel de derechos de imagen, ticketing, merchandising y de apertura de centros para encontrarse con el fan, como el que tenemos nosotros en Málaga, el Home of Giants, que es la sede de nuestro club de esports Vodafone Giants.

\footnotetext{
Entrevista realizada por Antonio José de la Cuesta (Twitter: @adelacues). Psicólogo colegiado M-27156, Experto en Psicología del Deporte (COP-España), Psicología Coaching Deportivo (Colegio Oficial de la Psicología de Madrid) y Psicología y Esports (Colegio Oficial de la Psicología de Madrid). Psicólogo en Residencias de Mayores y Centros de Día, diferentes deportes y esports (LoL, COD y CSGO). Miembro Grupo Trabajo Psicología, Videojuegos y Esports (Colegio Oficial de la Psicología de Madrid)
} 
En noviembre de 2020 se firmó el convenio de colaboración entre la Asociación de Clubs de Esports (ACE) y el Colegio Oficial de la Psicología (COPM). ¿Qué puede aportar a ambas partes?

Ambas partes se realimentan continuamente. Por un lado, los profesionales del Colegio Oficial de la Psicología de Madrid aportan sus conocimientos, mientras que los equipos participan continuamente en competiciones que requieren el $100 \%$ de las habilidades de los jugadores, de ahí que sea importante este apoyo de profesionales de la psicología para, no solo la mejora del rendimiento, sino para un desarrollo mental adecuado. Con la colaboración de ambos, los resultados serán más positivos y seguiremos afinando en la búsqueda de los mejores métodos de entrenamiento y preparación para los jugadores profesionales.

A partir del convenio con ACE, el COPM ha creado un Grupo de Trabajo en Psicología, videojuegos y esports, y ha impulsado la formación especializada de psicólogos/as en los esports. ¿Cuáles son las principales necesidades psicológicas en los clubes profesionales de esports? ¿Qué puede aportar un psicólogo/a?

El rendimiento deportivo es la base de toda competición y por lo tanto para el buen funcionamiento del club y la organización en general. Para un buen rendimiento es necesario también trabajar en la lectura de emociones, en la toma de decisiones, cómo enfrentarse a los desafíos, a la frustración de la derrota, también a las críticas... Para esto, es habitual contar con la figura del psicólogo en los clubes de esports.

Desde ACE se está impulsando la participación de los clubes amateurs y semiprofesionales. ¿Cuáles son las principales necesidades psicológicas en los clubes no profesionales de esports? ¿Qué puede aportar un psicólogo/a?

Pues podemos ligarlo a la pregunta anterior. También en los circuitos no profesionales hay un componente competitivo importante y hay que saber lidiar con ello.

Dentro del mundo de los videojuegos y junto a los esports tenemos el concepto "Gaming", más relacionado con el entretenimiento, como los creadores de contenido o streamers. ¿Qué necesidades tienen? ¿Cómo se puede contribuir desde la Psicología?

Es esencial poder prestarles un servicio de acompañamiento durante su carrera en los clubes. Fomentando un buen clima entre la entidad y el creador, conseguiremos que los niveles de estrés disminuyan, conseguiremos que logren hacer comunidad, que amplíen su capacidad de comunicación, que cuajen relaciones de confianza con sus responsables en el club. Trabajar con ellos la autoestima mejora su rendimiento y les da posibilidades de crecer como profesionales.

Tu rol profesional también se ha ligado a la promoción de la mujer dentro de los esports. ¿Cuál es el estado actual de esta cuestión? ¿Cuáles son los grandes retos a conseguir en los próximos años?

Tenemos que seguir trabajando. Es cierto que las mujeres ocupan una parte muy importante de la audiencia en los esports, hay estudios que cifran ese seguimiento en casi un $40 \%$ del total del mercado. Tenemos que promocionar a la mujer a nivel profesional y competitivo, ofrecerles oportunidades, generar visibilidad. En Vodafone Giants tenemos equipo femenino (ahora en Valorant, anteriormente en Counter Strike) y diversos programas de integración de las chicas en competiciones de videojuegos que están funcionando bien y seguiremos ampliando horizontes.

Desde tu opinión, una mujer gamer o entrenadora de esports, ¿qué necesidades tiene? ¿en qué puede ayudarle un psicólogo/a?

Tiene que tener oportunidades. Tengo la impresión, hablando con muchas de ellas, de que las mujeres que han jugado o consumido videojuegos no han sido demasiado respaldadas en casa. Al final se trata de un cambio cultural que hay que perseguir, como el respeto a sus particiones y eliminar cualquier elemento tóxico en chats o redes.

Para finalizar, nos gustaría que pudieras compartir un mensaje para los psicólogos/as del deporte que tienen interés en los esports.

Es primordial enseñar a los/as jugadores/as a reconocer las emociones relacionadas con la competición: euforia, ale- 
gría, rabia, tristeza, ira... Cada uno de estas emociones generan respuestas diferentes, por lo que se debe trabajar en equipo para poder saber actuar en determinados momentos. De esta manera ayudaremos a combatir el desgaste mental que supone el entrenamiento, la exposición constante y la competición para un profesional de la élite de los esports, que es con quienes tratamos cada día. 